\title{
Looking beyond the magic bullet: Novel asthma drugs or education, which works better?
}

R Masekela, ${ }^{1} \mathrm{PhD}$; M Levin, ${ }^{2} \mathrm{PhD} ;$ P M Jeena, ${ }^{1} \mathrm{PhD} ;$ M Annamalai,${ }^{3}$ Cert Pulmonology (SA) Paed; V Naidoo, ${ }^{1}$ Cert Pulmonoogy (SA) Paed; A van Niekerk, ${ }^{4}$ Cert Pulmonology (SA) Paed; D Hawarden, ${ }^{5} \mathrm{MB}$ ChB; S Emanuel, ${ }^{6}$ MB ChB; H Katz, ${ }^{7}$ BSc Hons Soc Work; H Zar, ${ }^{2}$ PhD; R J Green, ${ }^{4}$ PhD, DSc; F E Kritzinger, ${ }^{8}$ Cert Pulmonology (SA) Paed; A I Manjra, ${ }^{9}$ FCPaed (SA), M Clin Pharm; on behalf of the South African Childhood Asthma Working Group (SACAWG)

\author{
${ }^{1}$ Inkosi Albert Luthuli Central Hospital and Department of Paediatrics and Child Health, School of Clinical Medicine, College of Health Sciences, \\ University of KwaZulu-Natal, Durban, South Africa \\ ${ }^{2}$ Department of Paediatrics and Child Health, Red Cross War Memorial Children's Hospital, and Medical Research Council Unit on Child and \\ Adolescent Health, Faculty of Health Sciences, University of Cape Town, South Africa \\ ${ }^{3}$ Private practice, Lenmed Ethekwini Hospital and Heart Centre, Durban, South Africa \\ ${ }^{4}$ Steve Biko Academic Hospital and Department of Paediatrics and Child Health, School of Medicine, Faculty of Health Sciences, \\ University of Pretoria, South Africa \\ ${ }^{5}$ Division of Allergology, Department of Medicine, Groote Schuur Hospital and University of Cape Town, South Africa \\ ${ }^{6}$ Private practice, The Asthma Clinic, Cape Town, South Africa \\ ${ }^{7}$ Allergy Live, Allergy Foundation South Africa \\ ${ }^{8}$ Netcare Christiaan Barnard Memorial Hospital, Cape Town; and Department of Paediatrics and Child Health, Faculty of Medicine and \\ Health Sciences, Stellenbosch University, Cape Town, South Africa \\ ${ }^{9}$ Private practice, Life Westville Hospital, Durban, South Africa
}

Corresponding author: R Masekela (masekelar@ukzn.ac.za)

\begin{abstract}
Although $<5 \%$ of children with asthma suffer from severe asthma, they account for the highest use of health resources. The field of asthma therapy is changing rapidly, with a number of new drugs and biologics being added to the treatment armamentarium, particularly for adults. This, though, is not the case for paediatric patients, in whom a number of these novel molecules and drugs have not been investigated. Even though adults have shown responses to medication in some studies, this does not necessarily imply that there will be similar results in children. In the management of severe asthma, use of specific interventions to ensure treatment adherence and goal-setting for selfmanagement is critical to ensure the best treatment outcomes. The objective of this article is to review and grade the current evidence base for use of novel asthma drugs and to make evidence-based recommendations for their administration in children with severe asthma in the South Africa context. We also review the evidence for medication-adherence strategies and self-management plans.
\end{abstract}

S Afr Med J 2018;108(8):619-623. DOI:10.7196/SAMJ.2018.v108i8.13163

Over the past decade, there has been an increase in new anti-asthma medications, particularly in biological agents recommended for adult asthmatics. ${ }^{[1]}$ Despite the increased access to novel agents, there has been a dearth of data and recommendations on the positioning of these drugs in the paediatric arena. Although children with severe asthma are a smaller component of the total asthmatic population $(<5 \%)$, there is a need for evidence-based recommendations for the use of these novel drugs in asthmatic children, as they consume a disproportionate amount of healthcare resources. ${ }^{[2,3]}$ Biological agents are typically recommended for use in specific asthma phenotypes and endotypes, with predefined criteria predicting treatment response. ${ }^{[4,5]}$

The role of asthma comorbidities and asthma education has been emphasised in the most recent international guidelines, with patient adherence and motivation forming a critical part of a package of care for asthma management and successful therapy. ${ }^{[1]}$

The purpose of this continuing medical education article is to review the current literature on novel asthma drugs and to assess the evidence for their use or avoidance in the paediatric age group. The role of asthma education and strategies to improve asthma outcomes are also reviewed.

\section{Methods}

The South African Childhood Asthma Working Group (SACAWG) convened in January 2017 to review the current available literature on novel treatments of asthma and asthma self-management plans (Appendix A). The scientific literature was assigned evidence levels according to the Grades of Recommendation Assessment, Development and Evaluation (GRADE) system (Appendix B).

\section{Novel asthma moleculles in South Africa Fluticasone furoate/vilanterol}

Few studies have been done in children with the new combination agent of an inhaled corticosteroid (ICS) and an ultra-long-acting beta-agonist. In 5 - 11-year-old patients with well-controlled asthma, fluticasone furoate/ vilanterol has a similar tolerability, safety profile, pharmacodynamic effect and pharmacokinetic profile as fluticasone furoate alone. ${ }^{[6,7]}$ The new combination drug is currently registered for children $>12$ years of age and recommended for children with moderate to severe asthma (evidence level B)

\section{Tiotropium bromide}

Tiotropium bromide is a once-daily long-acting anticholinergic drug initially approved for chronic obstructive pulmonary disease 
(COPD). In trials involving children, tiotropium improved lung function as an add-on treatment to ICSs. It may contribute towards preventing asthma exacerbations (evidence level B). ${ }^{[8]}$ It has a role only in those with severe asthma who do not respond to either mediumdose ICSs and long-acting beta-agonists (LABAs) or a combination low-dose ICS, LABA and leukotriene receptor antagonist (step 4). This drug is only recommended in children $\geq 12$ years old.

\section{Novel asthma therapies currently not recommended in South Africa Allergen immunotherapy}

The position of subcutaneous immunotherapy (SCIT) and sublingual immunotherapy (SLIT) as potential therapeutic options for asthma has yet to be clearly established in international asthma guidelines. ${ }^{[9,10]} \mathrm{A}$ meta-analysis of 98 studies found that SCIT significantly reduced asthma symptoms and medication use and improved bronchial hyperactivity, but demonstrated no effect on lung function, asthma control or exacerbation. ${ }^{[11]}$

SLIT has been proposed as a more feasible option compared with SCIT. A meta-analysis of 52 studies on SLIT in asthma revealed that there were limited data to draw any conclusions, given the lack of reporting of important outcomes, such as exacerbations and quality of life (evidence level III). ${ }^{[12]}$ Furthermore, the majority were mild or intermittent asthmatics, limiting the applicability of the results for severe asthmatics. Currently, in South Africa (SA), immunotherapy remains a relatively inaccessible and expensive treatment option for asthma and should not be considered as routine therapy.

\section{Monoclonal anti-IgE}

Omalizumab $(\mathrm{OM})$ is a recombinant DNA-derived humanised monoclonal antibody licensed for use in children $>6$ years of age. It binds to the Fc portion of the IgE molecule and decreases unbound IgE. There is good-quality evidence from large meta-analyses in moderate to severe asthmatics that shows a decreased exacerbation rate, decreased duration of hospitalisation and increased withdrawal of ICSs. ${ }^{[13,14]}$ In children $6-11$ years of age with severe allergic asthma, OM reduced clinically significant exacerbations but not severe exacerbations ${ }^{\left[{ }^{15]}\right]}$ During a 1-year study, OM was found to be safe, it increased quality of life and global evaluation of treatment effectiveness, and allowed complete withdrawal of steroids with no increase in adverse drug reactions (evidence level A). ${ }^{[16,17]}$ Evidence for the use of OM in children with severe persistent asthma is lacking, as most studies were conducted in moderate asthmatics. Predicting and evaluating response to $\mathrm{OM}$ in cases of severe asthma remain uncertain, as $\mathrm{OM}$ is equally beneficial in patients with low or high IgE levels and data in severe asthma are limited and based on anectodal evidence (evidence level D). Currently, use of this agent should only be on subspecialist recommendation, when all other causes of uncontrolled asthma have been investigated and ruled out and costs have been taken into consideration.

\section{Other biological agents}

Mepolizumab (anti-interleukin-5 (anti-IL-5)), reslizumab (anti-IL-5), lebrikizumab (IL-13) and dupilumab (anti-IL-4 receptor shared by IL-4 and IL-13) are newer monoclonal antibodies. Many trials with these drugs have been conducted in adult asthmatics, but there are not yet any published trials on paediatric asthma. These agents may be useful for severe uncontrolled asthma, but cannot currently be recommended owing to a lack of data and because of the cost.

\section{Bronchial thermoplasty}

There are no data on bronchial thermoplasty in children.

\section{Macrolides}

Macrolide antibiotics have antimicrobial and anti-inflammatory properties, which may benefit asthma control. The available evidence on macrolide antibiotic use in chronic asthma, and especially chronic paediatric asthma, is of low quality. Some patients with uncontrolled asthma have chronic Chlamydia pneumoniae, Mycoplasma pneumoniae or protracted bacterial bronchitis, which may contribute to lack of symptom control. Macrolide antibiotics may assist in the eradication of these infections and contribute towards the resolution of asthma symptoms. ${ }^{[18]}$

A recent systematic review and meta-analysis assessed the effects of macrolide antibiotics in chronic asthma. Macrolide treatment was not better than placebo for most clinical outcomes, including exacerbations requiring hospital admission (evidence level C). ${ }^{[19]}$ We should not lose sight of the risk for development of macrolideresistant bacteria. ${ }^{[20,21]}$ Current evidence therefore does not support the routine use of macrolides.

\section{Antihistamines}

Antihistamines have no benefit for asthma symptom control, but may be useful for control of symptoms of co-existing allergic diseases, such as rhinitis, conjunctivitis and atopic eczema, where topical therapy alone is insufficient to control symptoms.

\section{Vitamin D}

Several cross-sectional studies have shown that low serum levels of vitamin D are linked to impaired lung function, higher exacerbation frequency and reduced corticosteroid response. However, to date, vitamin D supplementation has not been associated with improvement in asthma control or reduction in exacerbations, although the quality of studies included in meta-analyses was low to very low (evidence level C). ${ }^{[22]}$

\section{Other drugs and therapies}

The following are of no benefit in the treatment of childhood asthma: antibiotics, cough syrups, mucolytics, ionisers and breathing exercises. Complementary and alternative medications and interventions bear insufficient evidence to permit recommendations. Physiotherapy is indicated in children only where lobar collapse is documented.

\section{Immunisation}

Influenza contributes to some acute asthma exacerbations, and patients with moderate to severe asthma should receive an influenza vaccination every year (evidence level D). ${ }^{[1]}$ However, vaccination does not reduce the frequency or severity of asthma exacerbations (evidence level A). There is no evidence for an increase in asthma exacerbations after vaccination with inactivated trivalent vaccines compared with placebo. People with asthma, particularly children and the elderly, are at higher risk of pneumococcal disease, but there is insufficient evidence to recommend routine pneumococcal vaccination in people with asthma (evidence level D). ${ }^{[1]}$

\section{Key strategies to manage poorly controlled asthmatics}

Reduction of exposure to avoidable triggers is encouraged, particularly where there is a clear association between exposure and symptoms. Environmental tobacco smoke (ETS) exposure is an important avoidable trigger of asthma exacerbations. There is significant evidence of chronic ETS exposure associated with asthma exacerbations in preschool children and suggestive evidence of this in older children (evidence level D). ${ }^{[23,24]}$ Indoor air pollution 
from the use of alternative fuel sources may be associated with asthma exacerbations. There is sufficient evidence that certain chemicals, such as nitrogen dioxide, increase airway responsiveness, but evidence is less clear with other chemicals. ${ }^{[25]}$ It is also vital to rule out potential comorbidities that could exacerbate asthma symptoms and result in poor asthma control (Table 1).

\section{Self-management plans and education Adherence}

Adequate adherence to a treatment plan is key for optimal therapeutic benefit. Adherence comprises distinct phases of treatment initiation, implementation (including the correct dosing, frequency and technique of administration) and persistence. A patient-centred approach that delivers holistic, empowering care that is tailored to the individual's priorities and needs is necessary to support adherence (Table 2).

The responsibility for patient education and support rests with the doctor, and should be shared with other trained healthcare professionals. Patients and parents must be encouraged to participate actively in their own management. The objective of this partnership is to enable asthma patients to gain the knowledge, confidence and skills to assume a major role in the management of their asthma. The partnership is formed and strengthened as patients and their healthcare professionals discuss and agree on the goals of treatment, and develop a personalised, written self-management action plan, including self-monitoring, and periodically review the patient's treatment and level of asthma control. The ability or willingness of patients to take responsibility varies and thus the information and skills training required by each patient differ. All patients require certain core information and skills, but most education must be personalised.

Educational programmes should be considered a part of routine care of all asthma patients. Asthma self-management education should be integrated into all aspects of asthma care and reinforced at each follow-up visit. Educational programmes significantly improve asthma control, quality of life and lung function testing, and decrease hospitalisation rates (evidence level A). The influence of education is greater in moderate-to-severe than mild-to-moderate asthma (evidence level A). Intensive education is of greater benefit than limited education, and written plans are superior to oral instructions (evidence level A). Education given at follow-up visits is more effective than education during emergency visits (evidence level A). Culture-specific programmes for asthmatic adults and children are more effective than generic programmes in improving quality of life, asthma knowledge, exacerbations and control (evidence level B). The current evidence base is not sufficient to assess the use of digital selfmanagement, such as smartphone and tablet computer applications for the delivery of asthma self-management programmes.

Strategies for effective education stress that the approach to the patient with an 'attentive listening technique' affects success of the intervention (evidence level C). A 'tell-back' approach, whereby

Table 1. Comorbidities that may result in poor asthma control

\begin{tabular}{lll}
\hline Disease & Diagnosis & Treatment \\
\hline Rhinoconjuctivitis/sinusitis & $\begin{array}{l}\text { Symptoms of itchy, runny or blocked nose } \\
\text { Allergic shiners, recurrent otitis media, pale enlarged } \\
\text { turbinates and conjuntivitis }\end{array}$ & $\begin{array}{l}\text { Allergen avoidance, education, intranasal } \\
\text { steroids, antihistamines, eye drops and } \\
\text { immunotherapy }\end{array}$ \\
Orevalence increasing in South African children & $\begin{array}{l}\text { Lifestyle modification, exercise and } \\
\text { psychosocial management }\end{array}$ \\
& Weight-for-age or BMI $>2$ standard deviations \\
GORD occurs in $80 \%$ of asthmatic children & Proton pump inhibitors \\
Allergic bronchopulmonary aspergillosis & $\begin{array}{l}\text { No gold standard diagnostic test } \\
\text { 25\% of poorly controlled asthmatics } \\
\text { Total IgE elevated, positive immediate skin test and } \\
\text { elevated serum IgE and/or IgG for Aspergillus and } \\
\text { central bronchiectasis }\end{array}$ & $\begin{array}{l}\text { Systemic steroids (evidence level C) and } \\
\text { antifungals }\end{array}$ \\
& & \\
BMI = body mass index; GORD = gastro-oesophageal reflux disease. &
\end{tabular}

Table 2. Methods to improve adherence

\begin{tabular}{|c|c|c|}
\hline Behavioural factors ${ }^{[26]}$ & Educational factors $^{[27,28]}$ & Other tools ${ }^{[29]}$ \\
\hline Evidence level B & Evidence level B & Evidence level C \\
\hline $\begin{array}{l}\text { Help parents to develop a behavioural chart } \\
\text { or reward system }\end{array}$ & $\begin{array}{l}\text { Age-appropriate explanation of the disease } \\
\text { process and treatment }\end{array}$ & $\begin{array}{l}\text { Asthma diaries to assess symptoms and } \\
\text { treatment administration }\end{array}$ \\
\hline $\begin{array}{l}\text { Help patients to link the administration of } \\
\text { medication with established daily activities }\end{array}$ & $\begin{array}{l}\text { Address real or perceived fears regarding } \\
\text { side-effects of medication }\end{array}$ & $\begin{array}{l}\text { Dose counters, canister weights and } \\
\text { prescription refills }\end{array}$ \\
\hline (e.g. meal time, brushing of teeth) & Motivational interviewing by healthcare & Electronic monitoring devices \\
\hline Help patients with setting alarms on cell & provider at follow-up visits & \\
\hline phones or watches & Consistent follow-up by the same & \\
\hline $\begin{array}{l}\text { Determine reasonable, specific goals defined } \\
\text { by the patient }\end{array}$ & healthcare provider & \\
\hline Reinforce patients in a positive manner & & \\
\hline Teach parents to offer labelled praise for & & \\
\hline adherence behaviour and ignore minor & & \\
\hline misbehaviour & & \\
\hline Help patients with introducing visible & & \\
\hline reminders at home & & \\
\hline
\end{tabular}


education is followed by a request for the patient to repeat the information to the practitioner, fosters better patient understanding (evidence level B). Using open questions and non-judgemental questioning may allow a more accurate measurement of adherence (evidence level C). For example, before questioning, acknowledging that most people have some degree of non-adherence and then asking how often the patient forgets to use their medication, may be more successful than simply asking how often medication is used.

The use of a personalised, written asthma action plan does not improve lung function, but does result in fewer days lost from work and school, fewer emergency department visits and hospital admissions, fewer nocturnal symptoms, less use of rescue medication and better quality of life (evidence level A). Asthma self-management plans may be based on symptoms and/or peak flows (depending on age and ability). Self-management plans based on symptoms are as effective as those based on peak flow measurement (evidence level A).

Acknowledgements. We acknowledge the hard work and contribution of the South African Childhood Asthma Working Group (SACAWG) members. We also acknowledge the huge contribution of the late Prof. Cas Motala, who was convener of the past three SACAWG guidelines.

Author contributions. RM: review, write-up and manuscript editing; PMJ, MA, VN, AIM, AvN, SE, HK, DH: conceptualisation, review, write-up and manuscript editing; and HZ, ML, RJG, FEK: write-up and manuscript editing.

Funding. SACAWG conducted a workshop, which received an unconditional educational grant from the Allergy Society of South Africa - funded by Novartis.

Conflicts of interest. None

. Global Initiative for Asthma. 2017. www.ginasthma.org (accessed 22 January 2017).

. Fainardi $\mathrm{V}$, Saglani $\mathrm{S}$. The need to differentiate between adults and children when treating severe asthma. Expert Rev Respir Med 2015;9(4):419-428. https://doi.org/10.1586/17476348.2015.1068693 3. Saglani S. Childhood severe asthma: New insights on remodeling and biomarkers. Paediatr Respir Re 2017;24:11-13. https://doi.org/10.1016/j.prrv.2017.06.001

4. Bush A, Saglani S. Management of severe asthma in children. Lancet 2010;376(9743):814-825. https:// doi.org/10.1016/S0140-6736(10)61054-9

5. Aldara MA, Saglani S. Mechanisms mediating pediatric severe asthma and potential novel therapies. Front Pediatr 2017;5:154. https://doi.org/10.3389/fped.2017.0015

6. Oliver A, van Buren S, Allen A, et al. Tolerability of fluticasone furoate/vilanterol combination therapy in children aged 5 to 11 years with persistent asthma. Clin Ther 2014:36(6):928-939. https://do. org/10.1016/j.clinthera.2014.03.014

7. Oliver AJ, Covar RA, Goldfrad CH, et al. Randomized trial of once-dialy vilanterol in children with asthma on inhaled corticosteroid therapy Respir Res 2016;17(1):37. https.//doi.org/10.1186/s12931-016$0353-4$

8. Vogelberg C, Moroni-Zentgraf P, Leonaviciute-Klimnatviciene M, et al. A randomised dose-rangin study of titropium Respimat in children with symptomatic asthma adespite inhaled corticosteroids. Respir Res 2015;16(1):20. https://doi.org/10.1186/s12931-015-0175-9
9. Global Initiative for Asthma. Global strategy for asthma management and prevention. 2016. www. inasthma.org (accessed 6 June 2018).

0. British Thoracic Society and the Seottish Intercollegiate Guidelines Network. British guideline on the managent of asthme. worbit-lho (acessed 10 June 2017)

Puy RM, Weiner JM, et al. Injection allergen immunotherapy for asthma. Cochrane Database Syst Rev 2010;4(8):CD001186. https://doi.org/10.1002/14651858.CD001186.pub

12. Normansell R, Kew KM, Bridgman AL. Sublingual immunotherapy for asthma. Cochrane Database Syst Rev 2015;(8):CD011293. https://doi.org/10.1002/14651858.CD011293.pub2

13. Normansell R, Walker S, Milan SJ, Walters EH, Nair P. Omalizumab for asthma in adults and children. Normansell R, Walker S, Milan S), Walters EH, Nair P. Omalizumab for asthma in adults and children. Cochrol D. 14. Rodigo G), Neflen H. Systemaic eview on the use of omalis A systematic review and economic evaluation. Health Technol Assess 2013;17(52):1-342. https://doi. org/10.3310/hta17520

16. Milgrom H, Fowler-Taylor A, Vidaurre CF, Jayawardene S. Safety and tolerability of omalizumab in children with allergic (IgE-mediated) asthma. Curr Med Res Opin 2011;27(1):163-169. https://doi.org

17. Lai $\mathrm{T}$, Want $\mathrm{S}, \mathrm{Xu} \mathrm{Z}$, et al. Long-term efficacy and safety of omalizumab in patients with persistent uncontrolled allergic asthma: A systematic review and meta-analysis. Sci Rep 2015;5(1):8191. https:// oi.org/10.1038/srep08191

18. Martin RJ, Kraft M, Chu HW, et al. A link between chronic asthma and chronic infection. J Allergy Clin Immunol 2001;107(4):595-601

9. Kew KM, Undela K, Kotortsi I, Ferrara G. Macrolides for chronic asthma. Cochrane Database Syst Rev 2015;(9):CD002997. https://doi.org/10.1002/14651858.CD002997.pub4

20. Earl CS, Keong TW, An SQ, et al. Haemophilus influenza responds to glucocorticoids used in asthma therapy by modulation of biofilm formation and antibiotic resistance. EBMO Mol Med 2015;7(8):101810133. https://doi.org/10.15252/emmm.201505088

21. Brusselle GG, Joos G. Is there a role for macrolides in severe asthma? Curr Opin Pulm Med 2014;20(1):95-102. https://doi.org/10.1097/MCP.0000000000000017

22. Faraes MM, Alkhaled LH, Mroueh SM, Akl EA. Vitamin D supplementation in children with asthma: A systematic review and meta-analysis. BMC Res Notes 2015;8(1):23. https://doi.org/10.1186/s13104014-0961-3

23. Magnus MC, Haberg SE, Karlstad O, Nafstad P, London SJ, Nystad W. Grandmother's smoking when pregnant with the mother and asthma in the grandchild: The Norwegian Mother and Child Cohort Study. Thorax 2015;70(3):237-243. https://doi.org/10.1136/thoraxjnl-2014-206438

24. Silvestri M, Franchi S, Pistorio A, Petecchia L, Rusconi F. Smoke exposure, wheezing, and asthma development: A systematic review and meta-analysis in unselected birth cohorts. Pediatr Pulmonol 2015;50(4):353-362. https://doi.org/10.1002/ppul.23037

25. Kanchongkittiphon W, Mendell MJ, Gaffin JM, Wang G, Phipatanakul W. Indoor environmental exposures and exacerbation of asthma: An update to the 2000 review by the Institute of Medicine, Environ Health Perspect 2015;123(1):6-20. https://doi.org/10.1289/ehp.1307922

26. Anderson WC, Szefler SJ. New and future strategies to improve asthma control in children. J Allergy Clin Immunol 2015;136(4):848-859. https://doi.org/10.1016/j.jaci.2015.07.007

27. Custovic A, Johnston SL, Pavord I, et al. EAACI position statement on asthma exacerbations and severe asthma. Allergy 2013;68(12):1520-1531. https://doi.org/10.1111/all.12275

28. Klok T, Kaptein AA, Brand PLP. Non-adherence in children with asthma reviewed: The need for improvement of asthma care and medical education. Pediatr Allergy Immunol 2015;26(3):197-205. https://doi.org/10.1111/pai.12362

29. Drotar D, Bonner MS. Influences on adherence to pediatric asthma treatment: $A$ review of correlates and predictors. J Dev Behavioral Pediatr 2009;30(6):574-582. https://doi.org/10.1097/DBP.0b013e3181c3c3bb

\section{Educational resources}

Educational materials may be accessed via the Allergy Foundation South Africa (www.allergyfoundation. co.za); Allergy Society of South Africa (ALLSA) (www.allergysa.org); National Asthma Education Programme (NAEP) (www.asthmasa.co.za); Global Initiative for Asthma (www.ginasthma.com); UK National Asthma Campaign (www.asthma.org.uk); US National Heart, Lung and Blood Institute (www. nhlbi.nih.gov/); National Asthma Council Australia (www.nationalasthma.org.au); and MedicAlert South Africa (www.medicalert.co.za). Because health literacy, language and culture may affect understanding of patient educational material, language-specific material (such as that available for South African languages (www.asthma.co.za)) is recommended.

Accepted 7 May 2018

\section{Appendix A. The SA Childhood Asthma Working Group (SACAWG) \\ Epidemiology: H Zar (leader), Western Cape; C Gray, Western Cape.}

Diagnosis of asthma: R Masekela (leader), KwaZulu-Natal; S M Risenga, Limpopo; O P Kitchin, Gauteng; P Goussard, Western Cape. Assessment of asthma control: R J Green (leader), Gauteng; A van Niekerk, Gauteng; D White, Gauteng; G Davis, Gauteng.

Pharmacotherapy: F E Kritzinger (leader), Western Cape; A Jeevanathrum, Gauteng; P de Waal, Free State; S Kling, Western Cape; A Vanker, Western Cape; T C Gray, Western Cape; J Morrison, Western Cape; A Puterman, Western Cape; E Zöllner, Western Cape; D Rhode, Western Cape. Pharmacotherapy - other therapies: A I Manjra (leader), KwaZulu-Natal; P M Jeena, KwaZulu-Natal; V Naidoo, KwaZulu-Natal; M Annamalai, KwaZulu-Natal; A van Niekerk, Gauteng.

Self-management plans: M Levin (leader), Western Cape; S Emanuel, Western Cape; D Hawarden, Western Cape; H Katz, Gauteng. 


\section{Appendix B. Level of evidence}

IA Evidence from meta-analysis and randomised controlled trials

IB Evidence from at least one randomised controlled trial

IIA Evidence from at least one controlled trial without randomisation

IIB Evidence from at least one or other quasi-experimental study

III Evidence from non-experimental descriptive studies, such as comparative studies, correlation studies and case-controlled studies

IV Evidence from expert committee reports, opinions or clinical experience of respected authorities

\begin{tabular}{lll}
\multicolumn{2}{l}{ Appendix B. Grades of Recommendation Assessment, Development and Evaluation (GRADE) } \\
\hline Level of recommendation & Quality of evidence & Definition \\
\hline A & High & $\begin{array}{l}\text { High-quality research very unlikely to change our confidence in the estimate effect based } \\
\text { on level I evidence } \\
\text { Moderate-quality evidence, where future research is likely to have an important impact } \\
\text { on our confidence in the estimate effect. Based on level II evidence or extrapolated from } \\
\text { recommendations from level I evidence }\end{array}$ \\
& Low & $\begin{array}{l}\text { Low-quality evidence, where future research is likely to have an important impact on our } \\
\text { confidence in estimate effect. Based on level III evidence or recommendations from } \\
\text { level I and II evidence } \\
\text { V }\end{array}$ \\
Very-low-quality evidence, where the estimate effect is uncertain. Based on level IV \\
evidence or recommendations from level I, II and III evidence
\end{tabular}

